\title{
Informed consent to HIV cure research
}

\author{
Danielle Bromwich, ${ }^{1}$ Joseph R Millum²
}

\begin{abstract}
${ }^{1}$ Department of Philosophy, University of Massachusetts Boston, Boston,

Massachusetts, USA

${ }^{2}$ Clinical Center Department of Bioethics/Fogarty International Center, National Institutes of Health, Bethesda, Maryland, USA
\end{abstract}

\section{Correspondence to} Dr Danielle Bromwich, Department of Philosophy, University of Massachusetts Boston, 100 Morrissey BLVD, Boston, MA 02125, USA; danielle.bromwich@umb.edu

DB and JRM contributed equally.

Received 2 October 2015 Revised 21 April 2016

Accepted 18 May 2016 Published Online First 10 June 2016

\section{CrossMark}

To cite: Bromwich $D$, Millum JR. J Med Ethics 2017:43:108-113.

\section{ABSTRACT}

Trials with highly unfavourable risk-benefit ratios for participants, like HIV cure trials, raise questions about the quality of the consent of research participants. Why, it may be asked, would a person with HIV who is doing well on antiretroviral therapy be willing to jeopardise his health by enrolling in such a trial? We distinguish three concerns: first, how information is communicated to potential participants; second, participants' motivations for enrolling in potentially high risk research with no prospect of direct benefit; and third, participants' understanding of the details of the trials in which they enrol. We argue that the communication concern is relevant to the validity of informed consent and the quality of decision making, that the motivation concern does not identify a genuine problem with either the validity of consent or the quality of decision making and that the understanding concern may not be relevant to the validity of consent but is relevant to the quality of decision making. In doing so, we derive guidance points for researchers recruiting and enrolling participants into their HIV cure trials, as well as the research ethics committees reviewing proposed studies.

\section{INTRODUCTION}

Case: Darius is a 35-year-old African-American man with HIV-1 infection. He takes daily Atriplaan all-in-one combination antiretroviral therapyand has an undetectable viral load and a CD4 count of 985 . When Darius tested positive 10 years ago he was deeply closeted and he considered his infection punishment for being gay. Without the post-test counseling and social support he received from an organization working with Black gay men, he doubts he would still be here. As a way of giving back, he volunteers as a treatment adherence counselor. But Darius wants to do more. A nearby academic medical center is recruiting HIV-positive participants for a trial transplanting genetically modified cells into participants who will be taken off their antiretroviral therapy. The purpose of the research is to test the safety of an intervention that might cure HIV. Darius understands the risks of interrupting his treatment, but after reading the consent form he is unsure about the risks of this experimental gene transfer. The form states that: "there may be adverse effects that are presently unknown and unforeseeable .... The possible consequences of the therapy are unknown. It could have no effect or a positive effect .... It could also possibly cause cancer, or even spread to your reproductive organs and be passed on to any future children you may have. However, to date no such events have been reported ... so this risk is still theoretical." Despite his uncertainty, Darius trusts the medical center and believes in the project, so he signs the consent form and enrols in the trial.
There is renewed interest in HIV cure research. Eradicating the virus from the immune system's memory cells or CD4 Tcells once seemed impossible, but Timothy Brown, the 'Berlin patient', has been functionally cured of HIV since $2007 .^{23}$ Others have experienced sustained periods of viral remission after either bone marrow transplantations or early antiretroviral treatments. ${ }^{4}$ Although a cure for HIV would be tremendously valuable, the early-phase trials currently in progress are controversial. In part, this is because they involve non-beneficial, high-risk interventions. Almost all are proof-of-concept trials that test the safety of high-risk interventions to clear latent HIV proviral reservoirs or confer HIV immunity, such as gene transfers or therapeutic vaccines. To collect preliminary evidence of efficacy, some involve treatment interruption. This increases the burdens and risks of study participation for participants like Darius. When people with HIV adhere to a lifelong antiretroviral regimen, they can achieve long-term viral suppression, effectively managing their infection as a chronic disease. Coming off the regimen increases the likelihood of rising viral loads and falling CD4 levels, which increases their vulnerability to opportunistic infection. There is also no guarantee that things will go back to normal when the study ends and treatment is restarted. Pausing treatment may increase the likelihood of developing HIV drug resistance and participants may not tolerate antiretroviral treatment as they did before or bounce back to pretrial health. ${ }^{5}$

Trials with highly unfavourable risk-benefit ratios for participants, like these HIV cure trials, raise questions about the quality of the consent of research participants. Why, it may be asked, would a person with HIV who is doing well on antiretroviral therapy be willing to jeopardise his health by enrolling in such a trial? A decision that appears so contrary to the participant's interests suggests to some that something must have gone awry in the decision-making process.

Three specific concerns about consent have been raised in the literature on HIV cure research. The first focuses on communication. Some commentators worry about the use of certain terms or phrases that they think have the potential to generate misconceptions or misunderstandings. ${ }^{6-8}$ For example, the use of the label 'HIV cure' to describe non-beneficial proof-of-concept research might be inappropriate, given the tendency of research participants in early-phase trials to overestimate the benefits of study participation. ${ }^{8}$ The research is increasingly focused on achieving sustained viral remission as opposed to a functional cure, ${ }^{9}$ which deepens the worry that this language is misleading. The second set of concerns are about participant 
motivation. Some commentators question whether enrolment decisions are truly voluntary when they are motivated out of a deep sense of obligation to the community, as Darius' was, rather than primarily for the medical benefit of the participant. ${ }^{10}$ The third set comprises concerns about understanding. Research participants frequently fail to recall facts about risk, uncertainty, and complex study designs and interventions. ${ }^{11} 12$ Given the nature of HIV cure research, some commentators have argued that all HIV cure trials should include a formal assessment of prospective participants' understanding of the trial's key features as part of the consent process. ${ }^{13}$

In this paper, we assess the validity of these concerns about consent and consider how they should be addressed. We distinguish two goals of the informed consent process-to obtain valid consent and to facilitate good decision making. We argue that the communication concern is relevant to the validity of informed consent and the quality of decision making, that the motivation concern does not identify a genuine problem with either the validity of consent or the quality of decision making and that the understanding concern may not be relevant to the validity of consent but is relevant to the quality of decision making. In doing so, we derive guidance points for researchers recruiting and enrolling participants into their HIV cure trials, as well as the research ethics committees (RECs) reviewing proposed studies.

\section{THE INFORMED CONSENT PROCESS}

The informed consent process has two central goals that are relevant to our concerns about risky trials. The first is an ethical requirement: to obtain valid consent. The second is an ethical aspiration: to facilitate good decision making.

The primary goal of the informed consent process is to obtain valid consent. All people have rights against interference with their bodies and property. In the absence of a very good reason, the violation of one of these rights constitutes a serious wrong. For example, if a researcher were to inject you with an experimental HIV vaccine without your permission, she would violate your rights. Competent adults, by virtue of their capacity for autonomous action, have the power to waive their rights against interference through giving consent. Valid consent can transform an act that would otherwise be a rights violation into no violation at all. Had you given valid consent to the researcher to perform exactly the same action, no rights violation would have occurred. Almost all clinical research involves acts that require consent. Hence, the valid consent of competent research participants is an ethical requirement for almost all clinical research.

A secondary goal of the informed consent process is to facilitate good decision making. An individual is more likely to make a good decision about study enrolment-that is, a decision that fits with his values and preferences-if he understands the information that is relevant to that decision. By disclosing what is known about the research in an understandable way and by making themselves available to answer questions or supplement the information disclosed, researchers provide prospective participants with the opportunity to make good decisions about enrolment. Although facilitating good decision making is a laudable goal of the informed consent process, there cannot be an ethical requirement to ensure that prospective participants make good decisions. A competent adult's right to decide for himself includes the liberty to make those decisions well or poorly. Unlike with small children, who lack the capacity to decide for themselves, other people may not force a competent adult to do what he has most reason to do. He is free to make his own decisions for his own reasons. Crucially, we will argue, the amount of information that potential participants must understand to give valid consent may be substantially less than they need to understand to make a good decision.

Two implications follow from this analysis. When enrolling a prospective participant, like Darius, into an HIV cure trial, the researcher is (1) required to obtain his valid consent, but (2) only encouraged to help him make a good decision. It would violate Darius' rights to enrol him if the researcher believes his consent is invalid, but not if she merely believes his decision does not reflect his values. Since the facilitation of high-quality decision making is not an ethical requirement of the informed consent process, other ethical considerations can trump it. For example, it would be unreasonable to expect a research team to achieve this aspirational ideal for all their research participants if doing so would be so costly that it would jeopardise the progress of socially valuable research.

With these goals of the informed consent process in mind, we now consider the concerns about consent to HIV cure research.

\section{THE COMMUNICATION CONCERN}

Certain aspects of research are hard to explain in lay terms. Others butt up against deep-seated misconceptions or false expectations. Take the poorly understood concepts of randomisation and double-blinding. Even the clearest explanation of the design of a double-blind randomised controlled trial would be unlikely to convey the study design to a prospective participant who began with the belief that his doctor would not have recommended study participation if he were not guaranteed to be in the treatment arm. Designing an informed consent process to achieve successful communication involves understanding which aspects of research are poorly understood and why. Only then can targeted efforts be made to escape potential participants' misconceptions and false expectations.

The large body of research on heuristics and cognitive biases identifies a variety of factors that influence decision making. ${ }^{14} 15$ In the clinical research context, certain cues may serve to signal that the activities are safe or familiar, which can prompt quick or less considered judgements about study enrolment. Others signal instead that the research is not as safe or familiar as it might at first seem, thereby motivating careful deliberation about study enrolment.

Some of these cues are surprisingly subtle. One study found that when a research study is described as a 'clinical investigation', as opposed to an 'experiment', participants assume a higher degree of certainty, fewer risks and a greater chance of individual benefit. ${ }^{16}$ The study did not assess whether these expectations were accurate, but even so Dubé et al recommend that HIV cure studies be described as 'experiments', so as to counter the tendency to underestimate the risks of study participation. ${ }^{9}$ Other surveys on consent forms for early-phase research find that information is often presented in vague, inconsistent and misleading ways. ${ }^{11} \quad 12$ 17-19 The consent form that Darius signs is a case in point. He is confused by the presentation of the gene transfer's unknown risks, and the experimental intervention is referred to as a 'therapy', which conveys a mixed message about the probability of individual benefit. Similar concerns apply to the phrase 'HIV cure research'. Given the goals of the research, the label seems misleading. ${ }^{9}$ Participants in early-phase trials tend to overestimate the benefits of study participation. ${ }^{20-23}$ Even if some trials are researching a functional cure, the worry is that the language of 'cure' might suggest an unwarranted prospect of being cured of HIV and so motivate some participants to take on excessive risks. 
The communication concern is a genuine threat to the validity of informed consent. To understand why, we must return to our previous discussion of valid consent. A competent adult has the right to control certain aspects of his own life, including what happens to his body. When another person exercises illegitimate control over his decisions about what happens to his body, this right is violated. Imagine that Darius has an acquaintance, Thora, who wants him to participate in an HIV cure trial. She threatens to divulge his HIV status to his family unless he enrols in the trial, so he does as she says. In this case, Thora coerces Darius into giving consent, which renders his consent invalid.

Coercion is one way in which one person can wrest agency from another; but it is not the only way. Suppose that Aaliyah is a member of the research team, responsible for drafting the consent form. She also has an interest in Darius enrolling in the study. Were she to withhold the risks of the experimental gene transfer from him, she would also exercise illegitimate control over his enrolment decision. She effectively denies him access to information that she knows and has reason to believe would be relevant to his decision. ${ }^{1}$ Exercising this kind of control undermines the voluntariness of his decision and can thereby invalidate his consent. ${ }^{24}$

In research, control through outright coercion or deception is rare. Darius is more likely to have his enrolment decision controlled by the way in which information is disclosed to him. We have already outlined some of the ways in which the consent form he signs fails to give him a fair opportunity to understand facts about risks and benefits that are probably relevant to his enrolment decision. Here is another example. Suppose that Aaliyah discloses everything she ought to, but does so using scientific jargon. The consent form is riddled with sentences like: "A risk of the experimental gene transfer is off-target mutagenesis." Most people do not know what that is, let alone how serious it is. Choosing to describe the risk in this way effectively denies participants access to information that is likely to be relevant to their enrolment decisions. If Darius consents to enrolment, Aaliyah may not have coerced him or lied by omission, but she has still undermined the voluntariness of his decision by inappropriate disclosure.

This analysis provides the first set of general guidance points for those overseeing and conducting HIV cure research. To respect a competent adult's right to make an enrolment decision for himself, a researcher ought to disclose all the information about the research that she has good reason to think may be relevant to a prospective participant's decision. If the research is actually focused on viral remission as opposed to a functional cure, she ought to avoid the language of cure. She ought to disclose the relevant information in the prospective participant's native or preferred language, at an appropriate level of complexity, using clear and consistent language, and with an eye to avoiding known sources of misconception or misunderstanding. She ought also to give him an opportunity to ask questions so that he can find out what she knows about anything else that he considers relevant to an enrolment decision. Otherwise put, HIV cure researchers, and RECs that oversee these trials, ought to ensure that the informed consent process gives prospective participants a fair opportunity to understand the information

\footnotetext{
${ }^{1}$ To exercise this kind of control she need not have a malevolent intention, she need only be responsible for withholding or misrepresenting information that is expected to be relevant to the decision being made.
}

that is relevant to making a good decision about study enrolment. This is an ethical requirement for obtaining valid consent.

\section{THE MOTIVATION CONCERN}

Not all participants misunderstand the research they are enrolled in. A patient enrolling in an HIV cure study may understand that he is taking on considerable risks and that he will not be cured of his infection. Like Darius, he may be motivated to enrol by a desire to give back. Given the rich history of activism and altruism among this particular patient population, HIV cure researchers expect many participants to be altruistically motivated. ${ }^{10}$ However, in order for their consent to be valid, it must be proffered voluntarily. The motivation concern is a worry about whether people who are motivated by such a strong sense of duty to benefit others are acting voluntarily. ${ }^{10}$

It is important not to reduce prospective participants' interests to medical interests or their reasons for acting to selfinterested ones. Non-beneficial, high-risk research is not in Darius' medical interests, but study participation may still further his non-medical interests. He clearly judges this research to be important and valuable; this is a project he wants to contribute to and be a part of. Moreover, we often have good reasons to help other people. Some of these reasons may constitute genuine moral obligations, while others may be supererogatory. Either way, there is nothing, in principle, more suspect about someone acting out of a desire to benefit others than out of a desire to benefit himself.

This analysis implies that the motivation concern does not identify a problem with the validity of consent to HIV cure research. A person motivated to enrol in a high-risk trial by a desire to benefit others may give perfectly valid consent. Those recruiting and overseeing research do have reason to be concerned about the validity of consent when illegitimate control has been exercised, such as via threats or manipulation. Given the risky nature of the research, RECs ought to require HIV cure researchers to ask prospective participants to explain why they have chosen to enrol. Provided that that explanation makes no reference to illegitimate control, the resultant token of consent ought to be accepted. As we have seen, altruistically minded participants, like Darius, can give very cogent explanations of why they are taking on risks for others. Researchers and RECs therefore should not prevent such an altruistically motivated person from enrolling if his proffered consent is otherwise valid and if he is otherwise eligible.

Consider now the relevance of being motivated by altruism to the second goal of the informed consent process. If someone values helping people with HIV through research, then allowing him to enrol in a study for altruistic reasons is improving his decision making. He is then better able to live his own life by his own lights. The motivation concern therefore does not identify a problem with the aspirational goal of facilitating good decision making either.

\section{THE UNDERSTANDING CONCERN}

A large body of evidence shows that participants have variable, but often poor, understanding of the research they have enrolled in. ${ }^{11}{ }^{12}$ For example, an interview study of participants in phase I cancer trials at a US Academic Medical Center found that only $31 \%$ understood the purpose of the research, even though $96 \%$ thought that they were well-informed before they agreed to participate. $^{22}$ Is it permissible to enrol willing individuals into risky HIV cure trials knowing that some are likely to have failed to grasp key aspects of the study? This is the understanding concern. 
When we turn to the two goals of the informed consent process, we find that they have differing implications regarding understanding. If the goal is to facilitate good decision making, participants should understand as many of the facts that are material to their decision as possible. These may include facts about the purpose of the research, the risks and potential benefits of study participation, the clinical alternatives to enrolment, other studies they might be eligible for, investigator conflicts of interest, and so forth. ${ }^{25}$ On the other hand, if the goal is merely to obtain valid consent, potential participants only need to understand what the acts are that they are being asked to consent to, not additional facts about the purpose for which these acts are being performed or about the acts' risks and benefits.

This last claim requires defence. In the research ethics literature, it is widely assumed that a lot of information needs to be understood to give valid consent to an act. ${ }^{26-30}$ The act's associated risks are usually among those facts. But it is possible to give valid consent to an act when ignorant of its risks. Consider an informed consent process in which Aaliyah, our HIV researcher, discloses information about the risks of an experimental gene transfer:

Unknown risk: Aaliyah knows that the experimental gene transfer has risks A and B. But unknown to her, it also has risk C. No scientist knows or has publicly hypothesized risk C. Aaliyah discloses that the experimental gene transfer has risks $\mathrm{A}$ and $\mathrm{B}$, and that there maybe further unknown risks. Darius consents to the gene transfer.

Assuming that Aaliyah's disclosure is otherwise impeccable, Darius' consent is valid. One goal of early-phase research is to learn about the risks of an experimental intervention. Consenting to study participation therefore involves consenting to acts for which some of the risks are unknown. Unknown risks illustrates that it is possible to give valid consent to an act without understanding its attendant risks.

Sometimes not being told about a risk does invalidate consent. Consider a variant on the case:

Undisclosed known risk: Aaliyah knows that the experimental gene transfer has risks A, B and C. She discloses A and B, but withholds C. Darius consents to the gene transfer.

Darius' consent is clearly invalid. He is also ignorant of a known risk, namely risk C. But Unknown risk shows that his ignorance of risk $\mathrm{C}$ is not sufficient to explain why his consent is invalid, since in both cases Darius is told and understands the same information. Instead, what makes the difference to the validity of his consent is the illegitimate control Aaliyah exercises over Darius in the second but not the first case. He is ignorant of risk $\mathrm{C}$ because Aaliyah voluntarily withholds this fact from him. Her illegitimate control invalidates his consent just as surely as fraud invalidates a contract. By contrast, she has no control over his decision in Unknown risk, because she does not know about risk $\mathrm{C}$ either.

What if she exercises no such control, yet Darius fails to understand what she knows and believes is relevant to his enrolment decision? Consider the following variant on our case.

Disclosed known risk: Aaliyah knows that the experimental gene transfer has risks A, B and C. She discloses all these risks and explains that there may be further unknown risks. Darius understands what the gene transfer involves, but having already decided to participate in the trial he stops paying attention to what Aaliyah tells him about the risks halfway through and doesn't process what she says about risk C. He signs the consent form ignorant of risk $\mathrm{C}$.

Assuming that Aaliyah's disclosure is otherwise impeccable, it may be unclear whether Darius' consent is valid. While we are not troubled by his failure to understand a fact that would be relevant to his enrolment decision but is unknown to all parties to the consent transaction, we may be troubled by his ignorance of facts that Aaliyah knows.

However, the analysis that explained our intuitions in the first two cases implies that Darius' consent is actually valid in Disclosed known risk. The relationship between disclosure and control explains our intuitions in Unknown risk and Undisclosed known risk. In Unknown risk, Aaliyah is in no better epistemic position than Darius with regard to risk C. She is therefore not in a position to exercise illegitimate control over his enrolment decision by withholding or misrepresenting this fact. In Undisclosed known risk, she is in a better epistemic position than Darius with regard to risk C, and she voluntarily withholds it despite having reason to believe that it would be relevant to his enrolment decision. She therefore exercises illegitimate control over this decision by withholding this fact. If we generalise from these cases, the analysis that explained our intuitions in the first two cases implies that Darius' consent is perfectly valid in Disclosed known risk. Aaliyah discloses everything she knows and believes is relevant to Darius' enrolment decision in a way that he could understand (just as he did understand risks $\mathrm{A}$ and $\mathrm{B}$ ) and thereby exercises no illegitimate control over his consent.

It might be objected that nothing in our analysis precludes the possibility that a fact about understanding might also explain the intuition. The bilateral nature of consent might tempt us to think that Darius needs to understand what Aaliyah knows about the research in order to give valid consent to study participation. But why think that this is true? It is natural to think that in order to give valid consent, Darius needs to understand all the true propositions about the research. But Unknown risk shows that this is impossible. And since some risks are unknown to all, Aaliyah has no epistemic access to this complete set of true propositions. It is therefore unclear why Darius' consent is invalid when he fails to understand facts that she understands. She, after all, is just another agent with imperfect knowledge about the research. As long as she discloses what she knows honestly and clearly-that is, she gives him a fair opportunity to understand-she discharges the duty not to invalidate his consent by way of illegitimate control. There is no further explanation that entails that we ought to hold the validity of his consent hostage to whether he understands what she happens to know about the research.

\section{IMPLICATIONS FOR HIV CURE RESEARCHERS AND RECS}

This analysis might seem to leave RECs and researchers rudderless, but it actually reveals options. To see this, consider a more troubling case:

Overly optimistic: Luis has a complicated relationship with his homosexuality and HIV status. He comes from a family and community that stigmatize both and lives in fear of being exposed as HIV-positive. Feelings of fear and shame motivated him to avoid testing, prevention and treatment services for many years, despite high-risk sexual encounters with older men. When Luis learns of the HIV cure trial, he is eager to enrol. "I could be the one who's cured!" he tells the research nurse conducting the initial screening.

When an HIV cure trial is otherwise ethical and in compliance with the regulations and guidelines, it might be ethically 
permissible to enrol a participant like Luis, even if his powerful desire to be rid of a stigmatising condition leads him to overestimate his chance of cure. Provided that he has been given fair opportunity to understand the risks and benefits, Luis' token of consent could still be valid.

However, the ethical aspiration to facilitate good decision making would not be met in this case. Provided that it does not impose excessive burdens on the research team or others, and provided that it does not interfere with any other ethical requirements, it would be laudable for researchers and RECs to do more to help potential participants to make good decisions. Here, we briefly outline a process by which they might do so.

Researchers and RECs might supplement the standard informed consent process with an extended discussion and require prospective participants to pass a comprehension test before enrolling. Everything we know about participant comprehension suggests that it is variable across a number of areas. ${ }^{11}$ But researchers and RECs are unlikely to improve overall understanding if they attempt to address too many areas of potential confusion in their extended discussions. ${ }^{31}$ Rather they ought to anticipate and prioritise the most serious misunderstandings or gaps in knowledge and discuss these with the prospective participant one-on-one. By testing the understanding of a potential participant, like Luis, after the study has been explained to him, some areas of misunderstanding can be identified. By then conversing with him, a researcher may come to understand what is motivating his enrolment decision and be able to address his misconceptions head on. Several systematic reviews find that extended discussions, particularly one-on-one conversations between a member of the research team and a prospective participant, have the most consistent results in improving poor understanding. ${ }^{11} 3233$

Although it would not violate Luis' rights to enrol him without testing his comprehension or engaging in re-education to facilitate good decision making, we recommend that researchers and RECs go through such a process when they have reason to think that prospective participants may harbour serious misunderstandings. It is true that such interventions would impede prospective participants' freedom of choice. After all, unless he exhibited substantial understanding, Luis would not be permitted to enrol despite proffering his valid consent. But this would not constitute an objectionable form of paternalism. No one, we assume, has a right to participate in a phase I HIV cure study and so it is permissible for researchers to refuse enrolment even to people who autonomously proffer their consent. For example, researchers may decide against enrolling Luis if his misconception is recalcitrant. The requirement would also add to the researchers' workload. But given the low numbers of participants in early-phase trials, these tests are not likely to overburden anyone or impede the progress of socially valuable research. Thus, even though the understanding concern does not threaten the validity of consent, it may still be worth addressing for the sake of benefiting the potential participants.

\section{CONCLUSION}

HIV cure trials have raised understandable concerns about the informed consent of HIV-positive participants. Here, we have distinguished three separate concerns: about how information is communicated to potential participants, about potential participants' motivations for enrolling in potentially high risk research with no prospect of direct benefit and about participants' understanding of the details of the trials in which they enrol.

The first concern is genuine: poor communication can threaten the validity of consent. The consent process should be designed so that potential participants are given a fair opportunity to understand the information that is relevant to their decision and, specifically, so that misconceptions about the likelihood of benefit are avoided. The concern about motivation does not threaten the validity of consent: there is nothing more problematic about being motivated by the interests of others than by one's own interests. The understanding concern is more complex. Though it is possible to give valid consent without understanding all the facts that might be relevant to one's decision, it is nevertheless a laudable aspiration for participants to understand enough to make a good decision by their own lights. In the context of early-phase HIV cure research, additional measures to improve understanding could benefit potential participants without imposing excessive costs or burdens on researchers.

Acknowledgements Thanks to Seema Shah, and the audience at Harvard Medical School's HIV Cure Workshop.

Disclaimer The ideas and opinions expressed are the authors' own. They do not represent any official position or policy of the U.S. National Institutes of Health or Department of Health and Human Services.

Contributors The authors jointly developed the argument, wrote, reviewed and revised the manuscript, and approved the final manuscript as submitted.

Funding National Institute of Allergy and Infectious Diseases (1 R56 Al114617-01). Clinical Center intramural funding.

Competing interests None declared.

Provenance and peer review Not commissioned; externally peer reviewed.

\section{REFERENCES}

1 Henderson GE. The ethics of HIV "cure" research: what can we learn from consent forms? AIDS Res Hum Retroviruses 2015;31:56-63.

2 Allers K, Hutter G, Hofmann J, et al. Evidence for the cure of HIV infection by CCR5Delta32/Delta32 stem cell transplantation. Blood 2011;117:2791-9.

3 Hutter $G$, Nowak D, Mossner M, et al. Long-term control of HIV by CCR5 delta32/ delta32 stem-cell transplantation. N Engl J Med 2009;360:692-8.

4 Persaud D, Gay H, Ziemniak C, et al. Absence of detectable HIV-1 viremia after treatment cessation in an infant. N Engl J Med 2013;369:1828-35.

5 Staunton C. Informed consent for HIV cure research in South Africa: issues to consider. BMC Med Ethics 2015;16:3.

6 Eyal N, Kuritzkes DR. Challenges in clinical trial design for HIV-1 cure research. Lancet 2013;382:1464-5.

7 Sugarman J. HIV cure research: expanding the ethical considerations. Ann Intern Med 2013;159:490-1.

8 Dubé K, Henderson GE, Margolis DM. Framing expectations in early HIV cure research. Trends Microbiol 2014;22:547-9.

9 Anderson JL, Fromentin R, Corbelli GM, et al. Progress towards an HIV cure: update from the 2014 International AIDS Society Symposium. AIDS Res Hum Retroviruses 2015;31:36-44.

10 Evans D. What would you do to cure HIV?. 25 May 2011 (cited 30 August 2015). http://www.aidsmeds.com/articles/hiv_cure_ethics_2042_20510.shtml

11 Flory J, Wendler D, Emanuel E. Empirical issues in informed consent for research. In: Emanuel $E$, ed. The Oxford textbook of clinical research ethics. Oxford; New York: Oxford University Press, 2008;645-60.

12 Mandava A, Pace C, Campbell B, et al. The quality of informed consent: mapping the landscape. A review of empirical data from developing and developed countries. JME 2012;38:356-65.

13 Lo B, Grady C. Ethical considerations in HIV cure research: points to consider. Curr Opin HIV AIDS 2013:8:243-9.

14 Tversky A, Kahneman D. Judgment under uncertainty: heuristics and biases. Science 1974;185:1124-31.

15 Kahneman D. Thinking, fast and slow. New York: Macmillan, 2011.

16 Advisory Committee on Human Radiation Experiments. Final Report. DC: US Government Printing Office, 1995.

17 King NMP, Henderson GE, Churchill LR, et al. Consent forms and the therapeutic misconception: the example of gene transfer research. IRB 2005;27:1-7.

18 Dresser R. First-in-Human trial participants: not a vulnerable population, but vulnerable nonetheless. J Law Med Ethics 2009;37:38-50.

19 Horng S, Emanuel EJ, Wilfond $B$, et al. Descriptions of benefits and risks in consent forms for phase 1 oncology trials. N Engl J Med 2002;347:2134-40.

20 Appelbaum PS, Lidz CW, Grisso T. Therapeutic misconception in clinical research: frequency and risk factors. IRB 2004;26:1-8. 
21 Joffe S, Cook EF, Cleary PD, et al. Quality of informed consent in cancer clinical trials: a cross-sectional survey. Lancet 2001;358:1772-7.

22 Daugherty CK, Banik DM, Janish L, et al. Quantitative analysis of ethical issues in phase I trials: a survey interview study of 144 advanced cancer patients. IRB 2000;22:6-14.

23 Daugherty C, Ratain M, Grochowski E, et al. Perceptions of cancer patients and their physicians involved in phase I trials. J Clin Oncol 1995;13:1062-72.

24 Bromwich D, Millum, J. Disclosure and consent to medical research participation. JMP 2015;12:195-219.

25 Gillies K, Skea ZC, MacLennan SJ, et al. Determining information for inclusion in a decision-support intervention for clinical trial participation: a modified Delphi approach. Clin Trials 2013;10:967-76.

26 Faden R, Beauchamp R, King N. A History and theory of informed consent. New York: Oxford University Press, 1986.

27 Levine R. Ethics and regulation of clinical research. Baltimore: Urban \& Schwarzenberg, 1986.
28 Beauchamp T, Childress J. Principles of biomedical ethics. New York: Oxford University Press, 2009.

29 The Council for International Organizations of Medical Sciences (CIOMS) in collaboration with the World Health Organization (WHO): The International Ethical Guidelines for Biomedical Research Involving Human Subjects. (Geneva, 2002).

30 World Medical Association, Declaration of Helsinki: Ethical Principles for Medical Research Involving Human Subjects. (Seoul: October 2008).

31 Morgan M, Fischhoff B, Bostrom A, et al. Risk communication: a Mental Models Approach. Cambridge: Cambridge University Press, 2002.

32 Flory J, Emanuel E. Interventions to improve research participants' understanding in informed consent for research: a systematic review. JAMA 2004;292: 1593-601.

33 Nishimura A, Carey J, Erwin PJ, et al. Improving understanding in the research informed consent process: a systematic review of 54 interventions tested in randomized control trials. BMC Med Ethics 2013;14:28. 


\section{Informed consent to HIV cure research}

Danielle Bromwich and Joseph R Millum

$J$ Med Ethics 2017 43: 108-113 originally published online June 10, 2016 doi: 10.1136/medethics-2015-103122

Updated information and services can be found at:

http://jme.bmj.com/content/43/2/108

\section{These include:}

References This article cites 23 articles, 3 of which you can access for free at: http://jme.bmj.com/content/43/2/108\#BIBL

\section{Email alerting} service

Receive free email alerts when new articles cite this article. Sign up in the box at the top right corner of the online article.

Topic Articles on similar topics can be found in the following collections Collections

HIV/AIDS (116)

Sexual health (150)

Informed consent (269)

Legal and forensic medicine (409)

Research and publication ethics (490)

\section{Notes}

To request permissions go to:

http://group.bmj.com/group/rights-licensing/permissions

To order reprints go to:

http://journals.bmj.com/cgi/reprintform

To subscribe to BMJ go to:

http://group.bmj.com/subscribe/ 